\title{
Orden interno, seguridad ciudadana y servicio secreto en el marco de la administración pública romana
}

\author{
Antonio FERnÁndez de BujÁN ${ }^{1}$
}

\section{RESUMEN}

Es preciso remontarse a la República romana para encontrar la primera manifestación de policía organizada, a la que se atribuye el control de la seguridad y el orden interno de la comunidad. A partir de entonces se habría producido una paulatina evolución hasta el burocratizado y especializado servicio de vigilancia y seguridad interna y externa en el Bajo Imperio.

Palabras clave: Vigilancia, Orden interno, Seguridad jurídica, Derecho administrativo, Derecho romano.

1 Catedrático de Derecho Romano de la Universidad Autónoma de Madrid, Madrid, España académico de número de la Real Academia de Jurisprudencia y Legislación, Medalla Castelao, premio de mayor prestigio otorgado por la Junta de Galicia ${ }_{i}$ Cruz de Honor de San Raimundo de Peñafort; Medalla de Oro del Colegio Nacional de Secretarios Judiciales; doctor bonoris causa por la Universidad de Plovdiv, Plovdiv, Bulgaria; pertenece a la Orden Civil de Alfonso X el Sabio, en la categoría de Encomienda con Placa Gran Cruz de la Orden de San Raimundo de Peñafort. Ha escrito 16 libros y más de doscientos cincuenta artículos en materia de derecho romano, derecho procesal y derecho civil, lo que le ha valido el reconocimiento de seis sexenios por la Comisión Nacional de Evaluación de la Actividad Investigadora (CNEAI). Entre sus libros destacan sus manuales Derecho público romano (19. ${ }^{a}$ ed., Civitas, 2016) y Derecho privado romano (9. ${ }^{a}$ ed., IUSTEL), que se han convertido en obras de referencia. Correo-e: antonio.bujan@uam.es Fecha de recepción: 25 de julio de 2016. Fecha de modificación: 2 de septiembre de 2016. Fecha de aceptación: 15 de septiembre de 2016. Para citar el artículo: Fernández de Buján, A. Orden interno, seguridad ciudadana y servicio secreto en el marco de la administración pública romana. Revista digital de Derecho Administrativo, n. ${ }^{\circ} 16$, segundo semestre, Universidad Externado de Colombia, 2016, pp. 29-50. DOI: http://dx.doi.org/10.18601/21452946.n16.04. 


\title{
Internal Order, Public Safety and Secret Service in the Roman Public Administrative Framework
}

\author{
ABSTRACT
}

The first instance of organized police can be found in the time of the Roman Republic, being tasked with looking after public security and internal order. A gradual evolution would thenceforth see it become the bureaucratic and specialized system of vigilance and internal as well as external security of the Late Empire.

Keywords: Vigilance, Internal Order, Legal Certainty, Administrative Law, Roman Law.

\section{OBSERVACIONES PRELIMINARES}

Es necesario remontarse a la República romana para encontrar la primera manifestación de policía organizada, a la que se atribuye el control de la seguridad y el orden interno de la comunidad, a partir de cual se habría producido una paulatina evolución hasta el burocratizado y especializado servicio de vigilancia y seguridad interna y externa en el Bajo Imperio, que habría jugado un relevante papel en el entramado político de la época.

Las convulsiones vividas en Roma en el último siglo de la República, la ausencia de su previsión y el fracaso de los medios utilizados para contrarrestarlas hicieron necesaria la intervención de las legiones, así como la decisión de César y, con posterioridad, de Augusto de crear un cuerpo de policía especializado y dotado de los medios materiales necesarios para hacer frente a la problemática planteada. Por otra parte, todo ciudadano tenía el derecho y el deber de defender el orden constitucional, mediante la denuncia y puesta en conocimiento de las autoridades competentes de las actuaciones que pudieran considerarse atentatorias contra la legalidad republicana.

A lo largo de la etapa del Principado se crearon una serie de magistraturas con competencias urbanas: el prefecto encargado del cuidado de la provisión y distribución de víveres, el cuerpo de vigiles, los curadores públicos, los encargados del cuidado de los edificios públicos, acueductos, espectáculos, moral pública, asociaciones, tribunales de justicia, etc. ${ }^{2}$. 
La configuración de la labor de policía como un servicio público, incardinado en el aparato administrativo estatal, es obra, en buena medida, de Augusto, que establece las bases de la policía urbana, provincial y judicial, con un criterio de jerarquía, de unidad de acción y de dirección permanente.

La labor de la policía augustea se desarrolla en dos campos de actuación estrechamente interrelacionados: un ámbito externo de investigación o espionaje, propio de la policía imperial o palatina, cuya dirección se atribuye al prefecto del pretorio o al magister officiorum, y un ámbito urbano, municipal o colonial, que comprende labores de orden y vigilancia local, bajo la dirección del prefecto de la ciudad y de los prefectos de las distintas localidades.

Con Vespasiano la policía de seguridad se atribuye al cuerpo de los denominados speculatores, y con Adriano esta labor se realiza por el cuerpo de los frumentarii, lo que comporta una mayor profesionalización como agentes encubiertos, del servicio secreto, con facultades de detención y encarcelamiento de los presuntos delincuentes, que debían ser puestos a disposición de la autoridad judicial o política para su enjuiciamiento, y respecto de cuya actuación se denunciaron numerosas irregularidades ${ }^{3}$.

Diocleciano disuelve el cuerpo de los frumentarii y crea el de los agentes in rebus, con mayores competencias y facultades, básicamente de seguridad, dirigido por el magister officiorum.

Entre las nuevas funciones de estos agentes estaban el control y la supervisión de los propios departamentos de la Cancillería imperial, lo que produjo, en ocasiones, espinosos enfrentamientos entre los funcionarios que integraban las correspondientes secciones. Particular atención cabe prestar a la labor de vigilancia, control y persecución de que durante siglos fueron objeto los cristianos por parte de los agentes secretos o encubiertos, a los que se les dio la denominación de beneficiarii y curiosi.

El análisis de la legislación imperial desde Constantino hasta Teodosio II y Valentiniano III recogida en el Código Teodosiano, así como los testimonios de las fuentes literarias, ponen de relieve la preocupación de los emperadores por alcanzar un difícil equilibrio entre el control y, en su caso, represión del ejercicio de las funciones asignadas a los agentes in rebus, a menudo realizadas abusivamente, y el reconocimiento de su actividad mediante la concesión de privilegios y beneficios. Por el contrario, la legislación imperial de León, Zenón y Anastasio recogida en el Código Justinianeo muestra a los agentes in

3 Con carácter general sobre la política municipal flavia, vid. MARÍA JosÉ BRAVO BOSCH, El largo camino de los bispani bacia la ciudadanía, Madrid: Dykinson, 2008; FEDERICO FERNÁNDEZ DE BUJÁN, La Betica, cornice privilegiata della legislazione municipale e coloniale dell'Hispania romana, RGDR, Iustel, n. ${ }^{\circ}$ 13, 2009 y JuAN Miguel AlbURQUERQUE SACRISTÁn, Concentración y ordenación urbanística del territorio romano: Colonias, conventos y municipios de la Bética, AA.VV. (ANTONIO FERNÁNDEZ DE BUJÁN, dir.), Hacia un derecho administrativo y fiscal romano, Madrid-Valencia: Dykinson, 2011, pp. 77-113. 
rebus plenamente integrados en la estructura burocrática de la administración imperial y con absoluto reconocimiento hacia el poder político, lo que conlleva la concesión o ratificación de privilegios por parte de los emperadores ${ }^{4}$.

La abundante legislación de Constancio sobre los agentes in rebus oscila entre el reconocimiento de su actividad y el consiguiente otorgamiento de beneficios, como sucede en el año 354 cuando a través de dos disposiciones les atribuye en exclusiva la supervisión del cursus publicus y les reconoce beneficios como el de la no inclusión en las curiae 5 , y la desconfianza y control, como en el año 355 por los encarcelamientos arbitrarios de que son autores sin tener en cuenta la competencia de los jueces ${ }^{6}$, o en el año 357 cuando, para impedir ciertos abusos, se reduce su número en provincias a $\operatorname{dos}^{7}$; en el mismo año se trata de reducir el uso abusivo de los servicios postales y establecerse mayor vinculación al poder central ${ }^{8}$. En el año 359, dos disposiciones regulan importantes expulsiones de la schola, justificadas por la inmoralidad de los agentes in rebus ${ }^{9}$.

Así mismo, de oscilante cabe calificar la posición de Juliano, pues mientras que en 362 respalda la actividad de los agentes in rebus en el cursus publicus ${ }^{10}, \mathrm{y}$ en 363 les exime de la incorporación a las curias municipales, únicamente extensivo a quienes hayan servido en palacio, si hubiesen cumplido tres años de servicio o se hubiesen licenciado durante el cuarto consulado del emperador, es decir, en $363^{[11]}$, conforme a las noticias suministradas por Libanio ${ }^{12}$ y Amiano Marcelino ${ }^{13}$, Juliano acomete una drástica e importante expulsión de agentes in rebus, al reducir su número a diecisiete y hacer uso incluso de sus propios servidores en calidad de confidentes.

De ordenancista se puede calificar la legislación de Teodosio a fin de obtener la máxima eficiencia de este servicio. Así reglamenta los ascensos, donde tienen participación los miembros de la schola, el magister officiorum y, por

Vid. JuAn ANTONIO ARIAS BONEt, Los "agentes in rebus". Contribución al estudio de la policía en el Bajo Imperio, AHDE, n. ${ }^{\circ} 27-28,1957-58$, pp. 199 ss.

5 C. Th. VIII.5.7; C. Th. VI.27.1. Sobre las exenciones locales, con carácter general, vid. MARÍa LUISA LÓPEZ HuGUET, Clasificación general de los "munera" locales y exposición de las principales causas de su exención, AA.VV., (ANTONIO FERNÁNDEZ DE BuJÁN, dir.), Hacia un Derecho Administrativo y Fiscal Romano, II, Madrid: Dykinson, 2013, pp. 565-574, id., "Munera civilia": tipología, sujeción y exenciones, RGDR, n. ${ }^{\circ} 20,2013$, pp. 1-17.

6 C. Th. VI.29.1. Vid. JosÉ LuIS ZAMORA MANZANO, La administración penitenciaria en el derecho romano: gestión, tratamiento de los reclusos y mejora de la custodia carcelaria, Madrid: Dykinson, 2015, p. 68.

7 C. Th. VI. 29. 2.

8 C. Th. VIII. 5. 9.

9 C. Th. VI. 29.3 y 5.

10 C. Th. VIII. 5. $14=$ C. J. 12. 50. 4.

11 C. Th. VI. 27. 2.

12 Lib., Or. I. 190: 568.

13 Amm. XXII 7. 5. 
supuesto, el propio emperador ${ }^{14}$; limita la autonomía individual de los agentes in rebus y aumenta su control ${ }^{15}$, lo que le lleva a impedir que puedan ejercer en sus lugares de origen ${ }^{16}$ y limitar el número de los dedicados al cuidado del cursus publicus ${ }^{17}$.

La legislación de Arcadio y Honorio se dirige, por una parte, a ordenar los ascensos ${ }^{18}$ y limitar la autonomía individual de los agentes in rebus ${ }^{19} \mathrm{y}$, por otra, a la concesión de privilegios y beneficios en favor de quienes ocupan los puestos más elevados en la matricula ${ }^{20}$. Cabe mencionar así mismo la legislación dirigida a erradicar los frecuentes abusos en los que incurren los agentes in rebus ${ }^{21}$.

Honorio y Teodosio II proceden así mismo a limitar la autonomía individual de los agentes in rebus y someterlos a un control más estrecho, bien de los gobernadores provinciales, bien del poder central ${ }^{22}$, llegando a expulsar a todos los curiosi $^{23}$, en su condición de inspectores de los servicios postales, por los abusos cometidos destacados en el litoral dálmata e islas adyacentes ${ }^{24}$.

Teodosio II y Valentiniano III se ocupan de privilegios y de aspectos relativos al principatus ${ }^{25}$, así como del número máximo de agentes in rebus que integran la matricula de la schola, que es limitado a $1.174^{[26]}$.

León I aborda en su gobierno básicamente la regulación de tres cuestiones:

- La competencia jurisdiccional del magister officiorum o su delegado, en materia civil o criminal ${ }^{27}$, sobre los agentes in rebus ducenarii y centenarii, limitadamente a la ciudad de Constantinopla, o al territorio provincial solo en el caso de que se encontrasen en misión oficial ${ }^{28}$;

C. Th. VI. 28. 2; C. Th. VI. 35. 9; C. Th. VI. 27. 5; C. Th. VI. 27. 6; C. Th. XIII. 5. 20; C Th. VI. 27. 3 .

C. Th. VI. $28.4=$ C. J. 12.21 .1$.

C. Th. VI. 28. 4.

C. Th. VI. 29. 7.

C. Th. I. 9. 3; C. Th. VI. 27.710 ; C. Th. VI. 27. 14.

C. Th. VI. 27. 11 ; C. Th. VI. 29. 8.

C. Th. VI. 27. 8 ; C. Th. VI. 27.12 y 13 ; C. Th. VI. 28.6.

C. Th. XI. 7. 17; C. Th. VI. 27. 15; C. Th. VI. 29. 10; C. Th. VI. 29. 12; C. Th. VI. 27. 17

C. Th. XI. 7. 17.; C. Th. VI. 27. 15.

23 Sobre los curiosi, vid. Gianfranco PuRPURA, I curiosi e la 'schola agentum in rebus', Palermo: S. Montaina, 1973, pp. 1 ss.

24 C. Th. VI. 29. 12.

25 C. Th.VI. 2. 21; C. Th. VI. 27. 20-22; C. Th. VI. 28.8.

26 C. Th. VI. 27. 23.

27 En relación con la quaestio de repetundis, vid. JUAN Miguel AlburQUERQUe SACRISTÁN, Fundamentos, evolución y aspectos más significativos de la "quaestio perpetua de repetundis". Concusión y corrupción, RGDR, Iustel, n. ${ }^{\circ} 24,2015$, pp. 1-25 
- La división en cinco grados de la matricula de la schola: ducenarii, centenarii, biarchi, circitores y equites ${ }^{29}, \mathrm{y}$

- Los servicios que deben realizar los agentes in rebus antes de acceder al principatus $^{30}$.

Zenón, en una pragmática sanción del año 484, regula detalladamente las sportulae que vienen obligados a pagar los principes agentum in rebus o los miembros de sus familias cuando son demandados en un proceso per libellum ${ }^{31}$.

Por último, Anastasio, en una constitución sin fecha, considera también a los agentes in rebus como clase privilegiada equiparada a los demás funcionarios palatinos a los efectos del pago de las sportulae, extendiendo dicho beneficio, entre otros, a las madres, esposas e hijos de los agentes. Si los anteriores beneficiarios viviesen en provincias, las tarifas se reducirían a la tercera parte de su cuantía ${ }^{32}$.

\section{ORIGEN, DESARROLLO, ESTRUCTURA Y FUNCIONES DEL CUERPO DE LOS AGENTES IN REBUS}

La primera mención de los agentes in rebus la encontramos en una constitución de Constantino del año $319^{[33]}$, si bien, como afirma un sector de la doctrina ${ }^{34}$ su origen puede ser anterior.

30 C. J. 12. 20. 5.

31 C. J. 12. 21. 8. Sobre la constitución y, en general sobre las costas procesales, vid., por todos, Alfonso Agudo Ruiz, Las costas en el proceso civil romano, Madrid: Dykinson, 2013.

32 C. J. 12. 20. 6. Vid., por todos, AlFOnSO AgUdo RuIZ, Las costas en el proceso civil romano, cit.

33 C. Th. VI. 35. 3. Vid. RonALD DelmaiRe, Largesses sacrées et res privata. L'aerarium impérial et son administration du IV au VI siècle, París-Roma: Collection de l'École Française de Rome, 1989, pp. 30 ss.; id., Les institutiones du Bas-Empire romain de constantin à Justinien. Les institutions civiles palatines, París: Cerf éditions du CNRS, 1995, p. 98, data la constitución en el 326.

34 OtTo HiRSChFeld, Die "agentes in rebus", Sitzungsberichte der Berliner Akademie, 1893, p. 442, ARTHUR EDWARD ROMILLY BOAK, The Master of the Offices in the Later Roman and Byzantine Empires, Studies Humanistic, XIV, 1924, p. 68; OTTO SEECK, s.v. Agentes in rebus, R.E. Pauly-Wissowa, I, 1894, col. 776; Juan Antonio ARIAS BONET, Los "agentes in rebus", cit., p. 198; NARCISO SANTOS, El servicio policial secreto romano en el Bajo Imperio según Ammino Marcelino, Memorias de bistoria antigua, 1, 1977, pp. 127 ss.; ROBERTO MOROSI, Il "princeps officii" e la "schola agentum in rebus", Humanitas, 31-32, 1980, pp. 26 ss.; ELENA QuinTANA ORIVE, La responsabilidad de los funcionarios públicos en Derecho Romano, Tesis Doctoral, UAM, pendiente de publicación. 
Según Aurelio Víctor ${ }^{35}$, Diocleciano organizó el cuerpo de los agentes in rebus asumiendo las funciones de los suprimidos frumentarii ${ }^{36}$-encargados del aprovisionamiento del ejército, como indica su propio nombre, del control del cursus publicus, es decir, de los servicios postales, y, quizá, de actividades de espionaje político-, que habrían degenerado en prevaricaciones, con el consiguiente desprestigio popular, lo que habría llevado a Diocleciano, parece que cediendo al deseo de la opinión pública más generalizada, a su supresión.

En un principio estos funcionarios serían soldados pertenecientes al ejército de Diocleciano y, como afirma Arias Bonet ${ }^{37}$, sometidos al mismo régimen que los demás elementos castrenses, lo que explicaría la ausencia en la mencionada época de disposiciones imperiales que regulasen su estatuto jurídico y sus competencias.

Los agentes in rebus, organizados en schola, se encuentran bajo la autoridad y el control del prefecto del pretorio ${ }^{38}$, para pasar en época de Constantino bajo la dependencia del magister officiorum, encargado de todas las scholae palatinae, incluida la de los agentes in rebus ${ }^{39}$, como revela el propio nombre con el que son conocidos, magisteriani, correspondiendo al praefectus praetorio únicamente el poder disciplinario sobre los agentes.

En opinión de Arias Bonet ${ }^{40}$, el mencionado cambio de dependencia funcional responde al deseo imperial de evitar el peligroso fortalecimiento de otros funcionarios, como podían ser los magistri militum o el praefectus praetorio. La vinculación de la schola a este último presentaba riesgos evidentes para el poder imperial, habida cuenta de que el praefectus praetorio mantuvo siempre su superior categoría aun con la merma sufrida en sus antiguas facultades, y por ello nada tiene de anómalo que se tendiese a evitar una excesiva concentración de atribuciones en él. Por otra parte, la sujeción de los agentes in rebus a

CAESARES, 39. 44.

36 Marcel Durry, Les cohortes pretoriennes, París: E. de Bocard, 1938, p. 28; OTTO FIEBIGER, s. v. Frumentarii, R. E. Pauly-Wissowa, VII.1, cols. 122-125; JuAn ANTONIO ARIAS Bonet, Los "agentes in rebus", cit., 198 nt. 4; NARCISO SANTOS, El servicio policial secreto romano, cit., pp. 127 ss., consideran que sería Domiciano quien los introdujo en el servicio estatal; Ronald SYME, The Imperial Finances under Domitian, Nerva and Trajan, JRS, 20,1930, pp. 55 ss.; ROBERTO MOROSI, Il "princeps officii", cit., p. 26 s., consideran que no sería hasta la época de Adriano.

37 JUAN ANTONIO ARIAS BONET, Los "agentes in rebus", cit., 199; igualmente, NARCISO SANTOS, El servicio policial secreto romano, cit., p. 128.

38 Así, Arthur Edward Romilly BoAK, The Master of the Offices, cit., p. 32; JuAn ANTONIO ARIAS BONET, Los "agentes in rebus", cit., pp. 205 ss.; WOLFGANG SEYFARTH, Römische Geschichte Kaiserzeit, 2, Berlín: Akademie, 1974, p. 354, NARCISO SANTOS, El servicio policial secreto romano, cit., pp. 128 ss. Vid. ROLAND DELMAIRE, Les institutiones du Bas-Empire romain, cit., p. 99.

39 LYDUS, Mag., II. 25.

40 JuAn ANTONio Arias Bonet, Los "agentes in rebus", cit., p. 206. 
los magistri militum habría producido el evidente peligro de concentrar en un sólo alto funcionario, poderes militares y policíacos.

El magister officiorum adquiere, conforme al nuevo estatus que se le reconoce en el marco de la administración imperial, un extraordinario poder, ya que, como afirma De Martino ${ }^{41}$, sus funciones son múltiples y difícilmente se pueden encuadrar en una sola rama de la administración.

Bajo el mando del magister officiorum ${ }^{42}$ se encuentran:

- Los sacra scrinia u officia palatina -scrinium memoriae, scrinium epistolarum, scrinium libellorum, scrinium dispositionum-, lo que le lleva a sustituir al prefecto del pretorio en la función de la seguridad personal del emperador, por lo que la guardia de palacio -scholae palatina- queda encuadrada bajo sus órdenes; por otra parte,

- Asume la dirección de las fábricas de armas;

- Se ocupa de las relaciones exteriores, recibiendo a los embajadores extranjeros y anunciando su llegada al emperador;

- Fija las fechas para las audiencias; y,

- Por supuesto, asume la dirección de la schola agentum in rebus.

III. ELMAGISTER OFFICIORUM Y LA SCHOLA AGENTUM IN REBUS. EL PAPEL DE LOS CURIOSI, LOS PRAEPOSITI CURSUS PUBLICI Y LOS CHARTULARII EN LA INSPECCIÓN Y ORGANIZACIÓN DEL TRÁFICO POSTAL Y EN LA SCHOLA NOTARIARUM

A partir de Constancio y Constante, salvo la excepción representada por el reinado de Juliano, hasta el año $390^{[43]}$, los poderes del magister officiorum se incrementan ya que los inspectores de los servicios postales -curiosi cursus publici-, hasta entonces reclutados de entre los palatini y no dependientes del magister officiorum, comienzan a ser seleccionados de entre los agentes in rebus ${ }^{44}$.

En el ámbito jurisdiccional, León, en el año $466^{[45]}$, atribuye competencia jurisdiccional al magister officiorum o a su delegado, en materia civil o criminal,

41 Francesco De Martino, Storia della costituzione romana, V, Napoli: Jovene, 1975, p. 289

42 Roberto Morosi, Il "princeps officii", cit., pp. 25 ss. Vid. Andrea Giardina, Aspetti della burocracia nel Basso Impero, Roma: Ateneo \& Bizzarri, 1977, pp. 55 ss.

43 C. Th. VI. 29.7.

44 C. Th. VI. 29. 2. Vid. JuAn ANTONIO ARIAS BONEt, Los "agentes in rebus", cit., pp. 206 ss., que cita además una inscripción, C. I. L., X. 7200, en la que se habla de un "ducenarius agens in reb(us) et p(rae)p(ositus) cursus publici"; GIANFRANCO PURPURA, I curiosi, cit., p. 22; NARCISO SANTOS, El servicio policial secreto romano, cit., p. 129.

45 C. J. 12. 20. 4. Sobre la constitución, vid. por todos, Agatina Stefania Scarcella, La legislazione di Leone I, Milán: Giuffrè, 1997, pp. 340 ss. 
sobre los agentes in rebus ducenarii y centenarii, limitadamente a la ciudad de Constantinopla, o al territorio provincial solo en el caso de que se encontrasen en misión oficial.

En opinión de Arias Bonet ${ }^{46}$, parece claro que el amplio poder de que de hecho goza el magister officiorum se deriva en gran parte de su ascendiente sobre los agentes in rebus. Este poder se manifiesta, además, no solo sobre la schola en cuanto organismo afincado en la respectiva capital, sino también en el mando que le corresponde sobre los deputati.

Por otra parte, a través de las actividades inquisitivas de esta red de agentes, llegaría el magister a informarse de secretos de todo tipo cuya posesión constituiría un arma poderosísima en el juego de la política.

Corresponde al magister officiorum proponer ${ }^{47}$ los candidatos al emperador para su ingreso en la schola, después de haber superado el examen sobre sus orígenes, costumbres y moralidad ${ }^{48}$, acreditar que saben leer y escribir, y que han recibido la aprobación de la mayoría de los miembros de la schola, si bien, a partir del 399, el emperador asume con exclusividad esta facultad ${ }^{49}$.

Eran admitidos en la schola, por privilegio, los hijos y hermanos de los principes ducenarii ${ }^{50}$, y estaban excluidos por incompatibilidad algunos funcionarios $^{51}$, así como los judíos, los samaritanos ${ }^{52}$, los herejes ${ }^{53}$ y los navicularii ${ }^{54}$.

Observa Arias Bonet ${ }^{55}$ que es difícil imaginar que en este aspecto su poder fuese ilimitado, y por ello sorprende que hasta el año $395^{[56]}$ no se requiera el beneplácito del emperador para las nuevas incorporaciones. Es admisible que con anterioridad a esa fecha la intervención imperial tuviese ya lugar, siquiera ocasionalmente y con carácter extraoficial, fuera de que el derecho de presentación para puestos en la schola es concedido en 396 a una serie de funcionarios diversos del magister officiorum. En lo que respecta a las expulsiones, se exige la previa autorización imperial desde Constancio en el año $359^{[57]}$. En el año

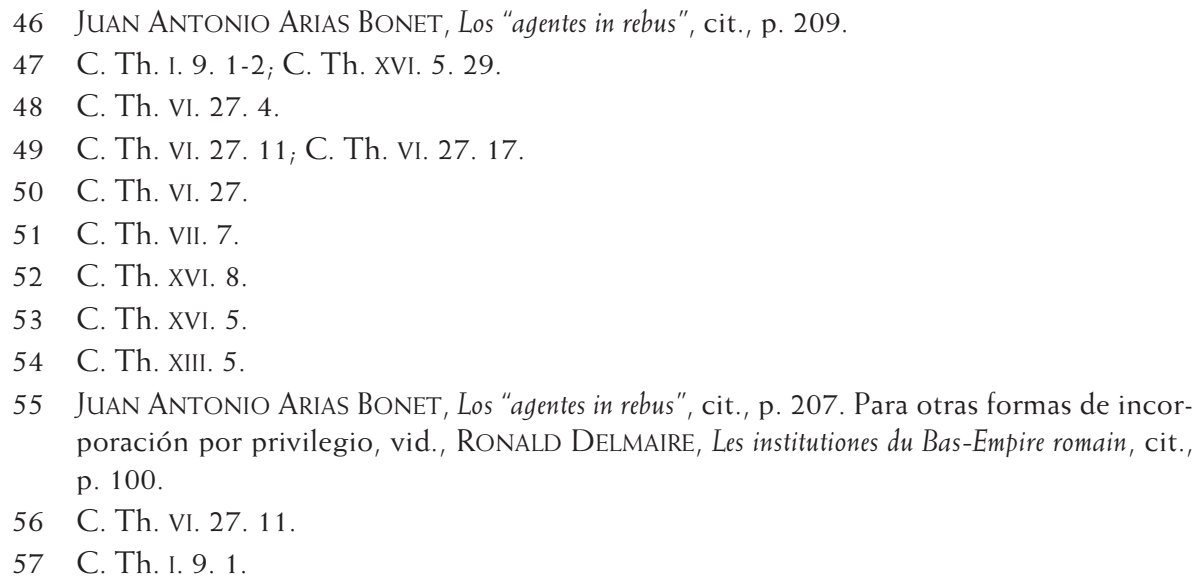


415, Honorio y Teodosio II recaban para sí esta facultad de destitución ${ }^{58}$, que posteriormente volverá al magister officiorum en el $416^{[59]}$.

Los agentes in rebus inscritos en la matricula de la schola se encuentran repartidos en distintas categorías o grados, bajo la supervisión del magister officiorum. En una constitución de Constancio ${ }^{60}$ del año 359 son citadas las tres categorías más importantes -ducena, centena, biarchia-.

En opinión de Arias Bonet ${ }^{61}$, no se puede determinar con exactitud el momento en que aparece tal discriminación, pero es muy probable que hubiera sido ya conocida en el tiempo de Constantino y acaso en el de Diocleciano. Desde luego abona esta suposición la terminología utilizada para designar las distintas categorías, pues las expresiones ducenarii, centenarii y biarcbi corresponden al lenguaje militar, lo cual lleva a admitir que los diferentes grados existían ya en la época en que se supone a los agentes in rebus íntimamente vinculados al ejército. Motivado por la corrupción en la que frecuentemente incurren los agentes in rebus, según Libanio ${ }^{62}$, Juliano redujo drásticamente su número a un total de 17. Teodosio II y Valentiniano III ${ }^{63}$, en el año 430, fijan en 1.174 el número máximo de los statuti de la schola. En el año 466, una disposición de León I ${ }^{64}$ organiza en cinco clases o rangos la schola agentum in rebus, los mismos que los utilizados en el ejército ${ }^{65}$, y cuyo número es limitado a: 48 ducenarii, 200 centenarii, 250 biarchi, 300 circitores y 450 equites, esto es, un total de 1.248 agentes in rebus.

Para los ascensos se tiene en cuenta la antigüedad en la matricula-matricula decurrente ${ }^{66}$, con la prohibición de los ascensos alcanzados por suffragium o por rescriptos obtenidos subrepticiamente, combinado con otros criterios como el

59 C. J. 6. 27. 18.

60 C. Th. I. 9.1 = C. J. 1. 31. 1.

61 Juan Antonio Arias Bonet, Los "agentes in rebus", cit., pp. 209 ss. En el mismo sentido, posición NARCISO SANTOS, El servicio policial secreto romano, cit., p. 129.

62 Lib., Or., 2. 58.

63 C. Th. VI. 27.23.

64 C. J. 12. 20. 3. Sobre la constitución, vid., por todos, AGATINA STEFANiA SCARCELLA, La legislazione di Leone I, cit., pp. 359 ss.

65 En este sentido, Giambattista Impallomeni, s.v. Agentes in rebus, NNDi, 1. 1, Turín, 1957, p. 400; JUAN ANTONIO ARIAS BONET, Los "agentes in rebus", cit., p. 210; GIANFRANCO PURPURA, I curiosi, cit., p. 36; ARNOLD HUGH MARTIN JONES, Il tardo Impero romano 284-602 d.C., trad. ital. Petretti, II, Milán: Il Saggiatore, 1974, pp. 807 ss.; FrAnCESCO DE MARTINO, Storia della costituzione romana, V, cit., p. 289; ROBERTO MOROSI, Il "princeps officii", cit., p. 29, RONALD Delmaire, Les institutiones du Bas-Empire romain, cit., p. 101; AGATINA STEFANIA SCARCELLA, La legislazione de Leone I, cit., $361 \mathrm{nt} .3$.

66 Vid. las fuentes citadas por RONALD DELMAIRE, Les institutiones du Bas-Empire romain, cit., 101 nt. 17 
arbitrio del emperador ${ }^{67}$. Delmaire ${ }^{68}$ observa que desde el año 380 las promociones especiales acordadas por el emperador se limitan a dos por año y por grado hasta aquel de circitor (C. Th. VI.27.3), igualmente, Arcadio confirma en 395 los ascensos concedidos por Teodosio para los agentes de rango inferior hasta el grado de los centenarii (C. Th. VI.27.7), o del magister officiorum ${ }^{69}$ o la decisión mayoritaria de los miembros de la schola. Como en las otras milicias, la ausencia prolongada fue sancionada en 379 con el retroceso de diez puestos por seis meses, y con la expulsión al cabo de cuatro años (C. Th. VII.12.2).

Los miembros de la schola, en opinión de Purpura ${ }^{70}$, pueden ser destinados a distintos cargos: así, en calidad de curiosi para inspeccionar el servicio postal, en calidad de praepositi cursus publici junto al officium del gobernador provincial, dirigiendo el tráfico postal en algunas provincias; en calidad de chartularii eran empleados en la schola notariarum, e igualmente en los departamentos centrales (sacra scrinia).

Como se ha afirmado, corresponde al magister officiorum la dirección de la schola agentum in rebus, si bien cabe pensar que debido a las múltiples funciones asignadas no ejerciera una dirección inmediata; por ello la doctrina se ha preguntado quién ostentaba la jefatura directa de la schola, sobre lo cual se han formado hipótesis muy elaboradas, entre las que cabe subrayar las siguientes.

Mommsen $^{71}$ distingue dos categorías de principes provenientes de la schola agentum in rebus: el princeps ex agentibus, agens in rebus no perteneciente ya a la schola, que dirigía el departamento de los prefectos, subordinado a estos, dejándolo de estar al magister officiorum, y el princeps officii, agente en servicio que dirigía los departamentos menos importantes.

Stein ${ }^{72}$ retoma la hipótesis de Mommsen, y distingue entre el principatus scholae agentum in rebus, jefe del departamento de los agentes in rebus, subordinado al magister officiorum, y el principatus officii, jefe de la sección burocrática de cualquier alto funcionario, independiente del magister officiorum y subordinado directamente al emperador.

$\mathrm{Su}$ tesis es asumida en sus líneas esenciales por Arias Bonet ${ }^{73}$, para quien un rasgo que se destaca claramente en cuanto nos enfrentamos con los textos que hacen referencia al princeps scholae es la creciente importancia de este den-

67

68

69

70

71 TheOdor Mommsen, Ostgotische Studien, Gesammelte Schriften, VI, Berlín, 1910, 412 ss.; VIII, Berlín, 1913, pp. 474 ss.

72 ERNST STEIN, Untersuchungen über das Officium der Prätorianerprefekten seit Diokletian, Amsterdam: A.M. Hakkert, 1962, pp. 140 ss.

73 JUAN ANTONIO ARIAS BONET, Los "agentes in rebus", cit., pp. 210 ss., seguida por NARCISO SANTOS, El servicio policial secreto romano, cit., pp. 129 ss. 
tro del sistema burocrático imperial. Ello resulta de las sucesivas ventajas y honores que se le atribuyen una vez que abandona el servicio activo. También entre los principes officiorum que proceden de la schola agentum in rebus tiende a aumentar el rango según van obteniendo el retiro. En este punto, mediante la mayor consideración de que goza el princeps scholae se pone de relieve la distinta índole de uno y otro principatus.

Subraya al respecto Arias Bonet que una constitución de Valentiniano I del año $367^{[74]}$ indica que ya en este año el princeps scholae, al dejar el servicio activo, entraba en la categoría de los clarissimi consulares, mientras que los principes officiorum, aún en el 380, no alcanzan más que el rango de los perfectissimi ${ }^{75}$. Cuando esta última clase de principes obtiene en el año $386^{[76]}$ la entrada en el grado de los clarissimi consulares se produce, en consecuencia, una equiparación con los principes scholae. Sin embargo, a partir de 390 se marcan de nuevo las distancias al comenzar a gozar estos últimos de la inmunidad de las cargas senatoriales $^{77}$, la cual se reconoce así mismo a los principes officiorum en una fecha posterior que no es posible fijar con exactitud, pero que puede situarse entre el año 396 y el 426.

Probablemente, antes de 410 las diferencias vuelven a ser ostensibles al serles concedida a los principes de la schola que dejan el servicio activo la categoría de spectabiles vicarii, pues en ese año alcanzan el más alto rango dentro de los spectabiles: el grado proconsular ${ }^{78}$. Evidentemente esto supone la previa consecución de la categoría de vicarii, a la que también llegan los principes officiorum algunos años más tarde, en el $426^{[79]}$.

Cabría pues afirmar ${ }^{80}$ que los principes scholae agentum in rebus acabarían siendo competentes en asuntos que no se referían propiamente a la estricta dirección de los agentes in rebus. Tal afirmación parece poder apoyarse principalmente en algunos pasajes de Lido (De mag. II.10; III.40; III.12) y de Amiano Marcelino (XV.3.7-11; XVI.8.3-7), de los que parece desprenderse que el princeps scholae agentum in rebus llegó a ostentar también simultáneamente la jefatura del officium del praefectus praetorio, por lo que una misma persona era a la vez princeps de los frumentarii o magistriani (es decir, de los agentes in rebus) y princeps officii de la prefectura del pretorio.

Subraya al respeto Arias Bonet que el testimonio de Amiano Marcelino prueba que al menos en el año 355 existe ya la acumulación, pues solo así se explican los acontecimientos que según este escritor tienen lugar por entonces.

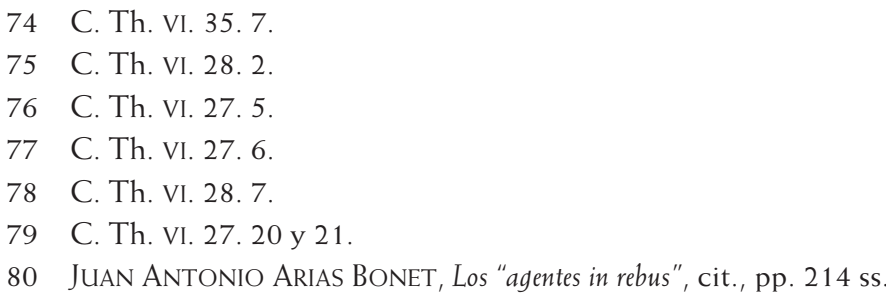


Según su relato, con ocasión de un supuesto crimen maiestatis cometido por el gobernador Africano (rector de Pannonia secunda), un agens in rebus, Gaudencio, es quien hace la correspondiente denuncia, dirigiéndose precisamente al apparitionis praefecturae praetorianae tunc principem. Este, llamado Rufino, va directamente a palacio y consigue la condena de los presuntos culpables (el gobernador y sus supuestos cómplices), siendo recompensado con un segundo año en el cargo. Tales hechos confirman la hipótesis de que el princeps officii de la prefectura del pretorio es al mismo tiempo el jefe efectivo de la schola agentum in rebus, y prueban asimismo la influencia de este personaje que no necesita de intermediarios para llegar hasta el propio emperador.

La vinculación del princeps scholae al officium del praefectus praetorio respondería probablemente, por otra parte, a la tendencia de minar en lo posible el ascendiente político de este, con arreglo a la táctica general ya seguida por Constantino de enfrentar unos funcionarios a otros. El praefectus praetorio se encuentra así vigilado estrechamente por un subalterno que le viene impuesto, el princeps, y que actúa en el officium de la prefectura del pretorio, no solo como jefe administrativo, sino también como espía. Este sistema debió de estimarse como altamente ventajoso. Una organización estatal como la que conoce el Bajo Imperio exige una vasta red de policías y de espías que no solo vigilen sectores extra estatales, sino también la propia máquina burocrática oficial en todos sus engranajes.

Sinnigen ${ }^{81}$ propone otra explicación. Distingue tres categorías de principes provenientes de la schola agentum in rebus: a) los ex agentes, encargados de los departamentos de las grandes prefecturas y subordinados directamente al emperador $;$ b) los principes scholae, jefes de la schola agentum in rebus; $y_{1}$ c) los principes, encargados de los departamentos menores. Considera ilógica la tesis de Stein: si el princeps officii de la prefectura en cuanto ex agente no formaba parte de la schola y no dependía del magister, ccómo podía dirigir a los agentes in rebus que constituían la schola si estaban sometidos al magister? Los principes scholae se deben identificar con los principes ducenae, e incluirlos en los 48 ducenarii de C. J. 12.20.3.

Frente a las teorías de Stein y Sinnigen, Giardina ${ }^{82}$ ha procedido a una revisión de las fuentes, llegando a la acertada conclusión según la cual, de la documentación relativa al rango de los principes officii provenientes de la schola agentum in rebus, no es posible llegar a la conclusión de la existencia de diversas categorías entre estos funcionarios. Contrariamente a Stein, demuestra que las diferencias de títulos y de privilegios no se deben al hecho de que haya dos clases de principes sino simplemente a una evolución diferente entre Oriente y

81 William GuRneE Sinnigen, The roman secret service, Classical Journal, 1961-62, pp. 65 ss.; id., Chiefs of staff and chiefs of the secret service, Byzantinische Zeitschrift, 57, 1964, pp. 78 ss.

82 Andrea Giardina, Aspetti della burocracia, cit., pp. 23-39. 
Occidente. Así el princeps officiorum obtendría el clarissimato inter consulares entre el año 367 y el 396 después del servicio; en el 410, en Occidente, con la dignidad proconsular; en el 426, en Oriente, con la dignidad vicariana.

Igualmente, Delmaire ${ }^{83}$ afirma que no existen dos clases de principes; la carrera normal de un agente finaliza cuando alcanza el rango de ducenari. En 417 después de veinte años de servicio, y con la aprobación de la schola, el agente que quiera retirarse, por razón de enfermedad o por cualquier otra causa, obtiene el título de princeps honorario, a partir de 435 después de veinticinco años. Los demás agentes in rebus pueden ocupar el cargo de subadiuvae en los scinia fabricarum y barbarorum, o el de ayudantes del primicerius y del tertiocerius en los sacra scrinia o, en fin, el de jefe de los departamentos del prefecto del pretorio y del urbano, de los procónsules de África y de Acaya, del comes Orientis, del praefectus Augustalis y de los vicarii.

El problema, como observa Delmaire ${ }^{84}$, es saber si permanecen como miembros de la schola o son borrados de la matricula cuando acceden a estos puestos. Algunas fuentes ${ }^{85}$ parecen hablar del princeps como de un agente en activo y sometido a la autoridad del magister officiorum, mientras que otras muestran que el cargo de princeps se obtiene al final del servicio de entre los agentes ducenarii. En su opinión, los agentes después de dos años como ducenarii reciben las insignias y honores de princeps, es decir, luego de haber terminado su servicio en la milicia (completa militia).

\section{LA ACTIVIDAD DE LOS AGENTES IN REBUS COMO POLICÍA SECRETA}

Por último, conviene abordar, así sea brevemente, un tema que ha despertado el interés de la doctrina, el relativo a la actividad de los agentes in rebus como policía secreta.

Un amplio sector de la doctrina considera que la schola agentum in rebus era un cuerpo que tenía como función principal la seguridad del Estado. Serrigny ${ }^{86}$, refiriéndose al magister officiorum, lo califica como ministro de la policía general. Impallomeni ${ }^{87}$ habla de una clase de empleados o funcionarios con prevalentes funciones de policía. Stein ${ }^{88}$, de cuerpos de policías. Piganiol ${ }^{89}$, de

RONALD Delmaire, Les institutiones du Bas-Empire romain, cit., pp. 112 ss.

RONALD Delmaire, Les institutiones du Bas-Empire romain, cit., pp. 112 ss.

Nov. Val. 8. 1.

Denis SerRigny, Droit public et administratif romain, París: Aug. Durand, Libraire-Éditeur, 1862, p. 87.

Giambattista IMPALlOMENI, s.v. Agentes in rebus, cit., p. 399.

ERNST STEIN, Histoire du bas-empire, I, París-Bruges: Hakkert, 1959, p. 113.

ANDrÉ PIGANIOL, L'empire chrétien, París: Presses Universitaires de France, 1972, p. 120. 
odiosa policía de Estado. Mazzarino ${ }^{90}$, de cuerpo de investigación. De Martino $^{91}$, de cuerpo de inspectores, una especie de policía de Estado al servicio del gobierno central, tal vez sus miembros han ejercido actividades de policía secreta, de espionaje político. Arias Bonet ${ }^{92}$ afirma que podemos suponer que en el régimen cuyas bases sienta Diocleciano no podía faltar una policía de carácter más o menos confidencial a cuyo cargo estuviese la vigilancia tanto de los sectores no propiamente estatales -si cabe hablar de sectores no estatales en el Bajo Imperio- como de la gran máquina burocrática de ese mismo Estado. Estas bajas actividades de carácter inquisitivo fueron encomendadas, como es sabido, a los llamados agentes in rebus, sin que falten en las fuentes no jurídicas claros testimonios de lo intolerable que en ocasiones debió llegar a ser la conducta de tales individuos. Para Santos ${ }^{93}$, la estructura política del Bajo Imperio romano, cuyas bases sentó Diocleciano, presuponía la existencia de un aparato estatal fuerte, en el que la organización de los servicios policiales debería jugar un enorme papel, este cuerpo de policía, más o menos confidencial, tendría bajo su cargo la completa vigilancia de la burocracia y la administración del Estado. El cuerpo especial de los agentes in rebus (agentes del servicio policial) no sirvió únicamente para el servicio de la correspondencia y las tareas normales de policía sino también para el control de la administración e, igualmente, de la opinión pública. Dicho cuerpo de policía tenía a su disposición la censura de la correspondencia, así como un extenso servicio de espionaje y delación. Estos policías estaban presentes en todas partes y, como afirma Amiano Marcelino, constituían una amenaza constante, que llevaba a soñar a todo hombre influyente con torturas, cadenas y obscuras mazmorras. Morosi ${ }^{94}$ considera que, sobre todo durante el reinado de Constancio II, los curiosi o curagendarii desarrollaron un verdadero y propio servicio de espionaje como agentes del servicio secreto; en efecto, en sus viajes a través de las provincias debían observar todo lo que ocurría y descubrir posibles conjuras contra el emperador.

Una de las principales fuentes en que dicho sector doctrinal se basa para apoyar su hipótesis de la función de policía secreta de los agentes in rebus es el conocido pasaje de Aurelio Víctor, De Caes., 39.44, que considera a los agentes in rebus como los sustitutos de los desaparecidos frumentarii, y que en opinión de Arias Bonet ${ }^{95}$ podrían haber heredado la misión de actuar como agentes secretos de la administración imperial. Constituyeron un grupo de carácter militar. Es explicable que los hombres de confianza requeridos para las deli- 
cadas funciones de información y ejecución que tienen a su cargo los agentes in rebus fuesen buscados por Diocleciano en su propio ejército.

Otra fuente citada para justificar misiones confidenciales y actividades de espionaje es Amiano Marcelino (XV.3.7.11; XVI.8.3-7), que para Arias Bonet ${ }^{96}$, según su relato, con ocasión de un supuesto crimen maiestatis cometido por el gobernador Africano (rector de Pannonia secunda), es un agens in rebus quien hace la correspondiente denuncia, dirigiéndose precisamente al apparitionis praefecturae praetorianae tunc principem. Este, llamado Rufino, acude directamente a palacio y consigue la condena de los presuntos culpables (el gobernador y sus cómplices). Tales hechos confirman la hipótesis de que el princeps officii de la prefectura del pretorio es al mismo tiempo el jefe efectivo de la schola agentum in rebus, y prueban de igual modo la influencia de este personaje que no necesita de intermediarios para llegar hasta el propio emperador. Añade Arias Bonet que el influjo de Rufino en el gobierno central se hace también patente en los intentos de eliminación del prefecto del pretorio Mavortio y del comes sacrarum largitionum Ursulo, hecho que se relaciona directamente con los turbios manejos policíacos del propio princeps officii de la prefectura.

Otro argumento destacado por Arias Bonet ${ }^{97}$ es la vinculación del princeps scholae al officium del praefectus praetorio, la cual responde, además, perfectamente a la tendencia de minar en lo posible el ascendiente político de este, con arreglo a la mencionada táctica general ya seguida por Constantino de enfrentar unos funcionarios a otros. Este enquistamiento del princeps de la schola en la prefectura del pretorio, con la finalidad de que actúe en esta, no solo como un modesto jefe administrativo, sino también en calidad de espía, no es más que un reflejo de lo que ocurría probablemente en las jefaturas de los officia de otros funcionarios de menos rango. Ahora bien, una organización inquisitiva de esta especie, llevada a sus últimos extremos, puede llegar a constituir una fuerza política tan formidable que el propio poder imperial, para cuya seguridad fue creada, se vea amenazado. Es así como se comprenden los cuidadosos escalonamientos jerárquicos y la organización interna del departamento de los agentes in rebus.

Frente a este sector de la doctrina, otros autores acertadamente mantienen la posición opuesta. Así, Jones ${ }^{98}$ afirma que tal idea estaba fundada sobre la actividad de ciertos miembros del cuerpo que se crearon una oscura fama durante el reinado de Constancio II indagando y denunciando conjuras de traiciones, reales o inventadas. Pero no es absolutamente verdad que fuesen los únicos con un temperamento sospechoso, también los notarii se ganaron una reputación bastante siniestra, y no hay razón para creer que los agentes in 
rebus en tiempos normales tuviesen funciones de policía, excepto como inspectores del servicio postal. Era un cuerpo humilde, no parangonable a los notarii por el prestigio social o la influencia política, y ninguno llegó a posiciones eminentes en el Estado.

Purpura ${ }^{99}$, el autor que más se ha detenido en este tema, ha revisado y objetado todos los argumentos que pretenden justificar a los agentes in rebus como miembros de la policía secreta. Respecto del pasaje de Aurelio Víctor, considera que quizá fuera solo su opinión personal sobre la institución de los agentes, influido por la práctica de la delación y las funciones inspectoras en el campo postal de los curiosi. No obstante, por la naturaleza de sus misiones oficiales no puede descartarse que ocasionalmente ejercieran funciones de espionaje; sin embargo, no es admisible la existencia de un reconocimiento oficial de actividades de espionaje y control atribuidas a un cuerpo determinado. La utilización, de hecho, para misiones confidenciales y de espionaje, de los agentes por parte de emperadores particularmente desconfiados, no parece, en efecto, corroborar la existencia de una "gebeime Staatspolizei", si con tal expresión se quiere aludir a un cuerpo oficialmente creado con la finalidad de proveer a la seguridad del gobierno central mediante el constante control de los súbditos y de los funcionarios. Aun cuando objetivamente es difícil distinguir la actividad de los mensajeros de aquella de los informadores, se puede afirmar que, al menos oficialmente, la schola no fue creada con la finalidad de realizar actividades de espionaje.

El examen de las fuentes postclásicas revela, en opinión de Purpura ${ }^{100}$, que las actividades de espionaje no fueron, ni tan siquiera de hecho, una prerrogativa exclusiva de los agentes in rebus, sino que para ello fueron preferidos los pertenecientes a otros cuerpos, como los miembros de la schola notariarum. Es cierto que el hecho de estar en continuo movimiento por el Imperio para transmitir los despachos oficiales, y la proximidad a la persona del emperador y el conocimiento de los secretos de Estado, favoreció la utilización de los agentes y de los notarii, con preferencia a otras categorías de funcionarios, para la ejecución de tareas confidenciales. Pero de esta circunstancia no se puede extraer la difusa conclusión de que fuesen miembros del servicio secreto.

Respecto de la simple presencia de un agens in rebus en un officium, considera Purpura ${ }^{101}$ que no puede interpretarse como un signo de injerencia de espionaje del gobierno central ni como una prueba de un directo control de los officia por parte de la schola agentum in rebus. Además, el nombramiento de princeps officii no era privilegio exclusivo de los miembros de la schola agentum in rebus; los componentes de los officia de los magistri militum, de los praefecti praetorio 
y del praefectus urbis podían ser nombrados principes de otros officia; y en otros officia, los principes eran elegidos de entre ellos mismos. Quizá, la atención que el poder imperial pone en la schola agentum in rebus se deba a la confianza que le merece al emperador, así como a su preparación y experiencia en el campo administrativo.

En este sentido afirma Morosi ${ }^{102}$ que, según la Notitia Dignitatum, para la elección del princeps officium no existía un criterio uniforme: así el princeps del procónsul de Asia, de los consulares y de los praesides en Oriente, de los correctores y de los praesides en Occidente, como de algunos duces en las dos partes del Imperio, eran elegidos de entre el personal del mismo officium ${ }_{i}$ en Occidente, para los consulares, era elegido del officium del praefectus praetorio Italiae; mientras para los comites y casi todos los duces, de aquel del magister militum praesentialis; en fin, para la mayor parte de los gobernadores (iudices) de rango de spectabiles, como los procónsules de Acaya y de África, el comes Orientis, el praefectus Augustalis, los vicarii, el comes limitis Aegypti y los duces de la frontera oriental, eran elegidos de la schola agentum in rebus o, mejor, de entre los ducenarii de la misma. Respecto a los magistrados más importantes de rango illustres, como los prefectos pretorianos y urbanos y los magistri militum praesentiales, tanto en Oriente como en Occidente, el origen de los jefes de sus officia es desconocido; no obstante se puede aceptar que el princeps de la prefectura pretoriana y urbana, al igual que aquel de los spectabiles iudices, provenían de la schola agentum in rebus.

Por último, observa Purpura ${ }^{103}$ que la no elevada posición oficial de los agentes in rebus en la rígida jerarquía burocrática y su limitada influencia no parece concordar con las importantes funciones de policía secreta y con el papel de instrumento del centralismo burocrático comúnmente asignados a la schola. La schola agentum in rebus, en conclusión, más que un omnipotente "servicio secreto" que controlaba todos los departamentos de la compleja estructura administrativa del Bajo Imperio, fue un útil cuerpo burocrático empleado en varios servicios. Los agentes asumieron principalmente la función, delicada e importante para el mundo antiguo, de mensajeros oficiales, y solo ocasionalmente fueron utilizados para misiones confidenciales y de espionaje. Los miembros de la schola podían ser destinados en varios cargos; en calidad de curiosi inspeccionaban el funcionamiento del servicio postal ${ }_{i}$ en calidad de praepositi cursus publici ayudaban en el officium del gobernador provincial ${ }_{i}$ en calidad de chartularii eran empleados en la schola notariarum, e igualmente podían ser asignados a los puestos más elevados de los departamentos centrales (sacra scrinia) cuando alcanzaban el grado de ducenarii. Ocasionalmente y junto con los notarii, domestici, protectores y los pertenecientes a otros cuerpos, podían ser encargados de realizar misiones confidenciales. 
Comparte la posición de Purpura, Giardina ${ }^{104}$, para quien los agentes aparecen investidos de competencias esenciales para la seguridad del Estado. Respecto al testimonio de Aurelio Víctor, considera este que refleja la opinión común del momento que veía en la schola agentum in rebus una directa continuación del cuerpo de los frumentarii, los cuales en los primeros tres siglos del Imperio se habían ganado una fama siniestra por sus actividades de espionaje. Subraya que no hay ninguna duda de que Constancio II utilizó ampliamente la capacidad investigadora de la schola agentum in rebus. Los agentes in rebus no intervienen solo en casos clamorosos y en denuncias de tentativas de traición, existen varios sectores en los cuales actúan para garantizar la seguridad política. Estos sectores son todos los que afectan a aspectos vitales del Estado, como las vías de comunicación ${ }^{105}$, las fábricas de armas o la transmisión de mensajes al jefe de los officia. Su presencia en estos sectores tenía como finalidad sofocar iniciativas de rebelión, pero no de menor importancia era el control del funcionamiento de la administración y de la aplicación de las leyes, uno de los puntos débiles del Estado del Bajo Imperio. La presencia de agentes in rebus - hombres expertos en el funcionamiento administrativo- en puestos de variada responsabilidad debía garantizar el desarrollo eficiente de un trabajo técnico, la inspección administrativa y el control político ${ }^{106}$.

Delmaire ${ }^{107}$ rechaza también la idea tradicional y caricaturesca de espías o de policía secreta; los agentes son mensajeros e inspectores que ejercen abiertamente su actividad, y cada uno de ellos sabe lo que debe hacer en los distintos cargos que desempeña; son los ojos del emperador, según Libanio (Or. 18.140). Sin embargo, algunos abusaron de su situación como mensajeros, como responsables del cursus, en la inspección de barcos, como princeps officium, lo que les hizo acreedores de una mala reputación.

\section{A MODO DE EPÍLOGO}

Cabría afirmar, en definitiva, a la vista de los abundantes testimonios contenidos en las fuentes romanas, que la conformación de la policía urbana, la policía exterior, la actividad de los delatores, el servicio de espionaje, la guardia

104 ANDREa GiaRdina, Aspetti della burocracia, cit., pp. 64 ss.

105 Vid. al respecto Vanessa Ponte ArRebOla, Régimen jurídico de las vías públicas romanas, Madrid: Dykinson, 2007, pp. 235 ss.

106 En relación con los magistrados y funcionarios, vid. MARÍA JosÉ Bravo BosCH, El "ius bonorum" en la antigua Roma, AFDUDC, 14, 2010, pp. 229-248, y ANDREA TRISCIUOGLIO, Consideraciones sobre la responsabilidad civil y administrativa del magistrado en la experiencia romana, AA.VV. (ANTONIO FERnÁNDEZ DE BujÁN, dir.), Hacia un Derecho Administrativo y fiscal romano, II, Madrid: Dykinson 2015, pp. 161-176.

107 Ronald Delmaire, Les institutiones du Bas-Empire romain, cit., pp. 117 ss. 
pretoriana, o el servicio palatino de seguridad, se presentan como un mosaico variopinto de investigación, al propio tiempo de represión, corrupción, transgresión de facultades ejercitadas, abuso de poder en el ejercicio de las labores legítimamente atribuidas, y al propio tiempo de seguridad jurídica, orden interno, control del aparato del Estado, vigilancia de los enemigos exteriores, que, paradojas y enseñanzas de la historia, nos acercan al panorama que es objeto de reiterada denuncia en los medios de comunicación de nuestro tiempo y en los tribunales de justicia, en relación con espionaje telefónico, programas de escuchas a particulares sin autorización judicial, espionaje en internet, venta de datos de información confidencial, corrupción de agentes de espionaje, etc.

Viejos ecos de conflictos entre el poder político, la legitimidad democrática y la razón de Estado, en el logro de mayores cotas de libertad, seguridad y justicia. Eterno y clásico retorno de problemas, principios e instituciones en el mundo del derecho.

La historia de la humanidad se nos presenta, también en este punto, como un proceso continuado y gradual, con sus hitos, altibajos y retrocesos, en la búsqueda de una regulación que haga compatible la necesaria seguridad de los Estados con el escrupuloso respeto de las libertades civiles y las garantías de los ciudadanos.

\section{BIBLIOGRAFÍA}

Agudo Ruiz, Alfonso. Las costas en el proceso civil romano, Madrid: Dykinson, 2013.

AlbuRQUERQUe SACRISTÁN, JUAN MIGUEL. Concentración y ordenación urbanística del territorio romano: Colonias, Conventos y Municipios de la Bética, AA.VV. (ANTONIO FERNÁNDEZ DE BUJÁN, dir.), Hacia un derecho administrativo y fiscal romano, Madrid-Valencia: Dykinson, 2011.

Alburquerque SACRISTÁN, JUAN Miguel. "Fundamentos, evolución y aspectos más significativos de la 'quaestio perpetua de repetundis'. Concusión y corrupción", RGDR, Iustel, n. ${ }^{\circ} 24,2015$, pp. 1-25.

Arias Bonet, Juan Antonio. "Los "agentes in rebus". Contribución al estudio de la policía en el Bajo Imperio", AHDE, n. ${ }^{\circ}$ 27-28, 1957-1958.

Boak, Arthur Edward Romilly. "The Master of the Offices in the Later Roman and Byzantine Empires", Studies Humanistic, XIV, 1924.

Bravo Bosch, María José. El largo camino de los bispani hacia la ciudadanía, Madrid: Dykinson, 2008.

Bravo BosCH, MARía JosÉ. "El 'ius honorum' en la antigua Roma", AFDUDC, 14, 2010. 
De Martino, Francesco. Storia della costituzione romana, V, Napoli: Jovene, 1975.

DELMAIRE, RONALD. Largesses sacrées et res privata. L'aerarium impérial et son administration du IV au VI siècle, París-Roma: Collection de l'École Française de Rome, 1989.

Delmaire, Roland. Les institutiones du Bas-Empire romain de Constantin à Justinien. Les institutions civiles palatines, París: Cerf éditions du CNRS, 1995.

DURRY, MARCEL. Les cohortes pretoriennes, París: E. de Bocard, 1938.

FERNÁNDEZ DE BujÁN, FEDERICO. "La Betica, cornice privilegiata della legislazione municipale e coloniale dell'Hispania romana", RGDR, Iustel, n. ${ }^{\circ}$ 13, 2009.

Fernández RosáEnZ, AUrora. "El cuerpo de vigiles", RGDR, Iustel, n. o 2, 2004.

Fiebiger, Otto. s. v. Frumentarii, R. E. Pauly-Wissowa, VII.1, cols. 122-125.

GiardinA, ANDREA. Aspetti della burocrazia nel Basso Impero, Roma: Ateneo \& Bizzarri, 1977.

HiRSCHFELD, OTto. Die "agentes in rebus", Sitzungsberichte der Berliner Akademie, 1893.

Impallomeni, GiambatTisTA s.v. "Agentes in rebus", NNDI, 1.1, Turín, 1957.

Jones, Arnold Hugh Martin. Il tardo Impero romano 284-602 d.C., trad. ital. Petretti, II, Milán: Il Saggiatore, 1974.

LÓPEZ HugUet, MARÍA LuISA. Clasificación general de los "munera" locales y exposición de las principales causas de su exención, AA.VV. (ANTONIO FERNÁNDEZ DE BujÁN, dir.), Hacia un derecho administrativo y fiscal romano, II, Madrid: Dykinson, 2013, pp. 565-574.

LÓPEZ HugUET, María LuISA. "'Munera civilia': tipología, sujeción y exenciones", RGDR, n. ${ }^{\circ} 20,2013$, pp. 1-17.

MAZZARINO, SANTO. L'impero romano, III, Roma-Bari: Laterza, 1973.

Mommsen, Theodor. Ostgotische Studien, Gesammelte Schriften, VI, Berlín, 1910, pp. 412 ss.

Morosi, Roberto. "Il 'princeps officii' e la 'schola agentum in rebus"'", Humanitas, $31-32,1980$.

Piganiol, André. L'empire chrétien, París: Presses Universitaires de France, 1972.

Ponte Arrebola, Vanessa. Régimen jurídico de las vías públicas romanas, Madrid: Dykinson, 2007. 
Purpura, Gianfranco. I curiosi e la schola agentum in rebus, Palermo: S. Montaina, 1973.

SANTOS, NARCISO. El servicio policial secreto romano en el Bajo Imperio según Ammino Marcelino, Memorias de Historia Antigua, 1, 1977.

QUINTANA ORIVE, ELENA. La responsabilidad de los funcionarios públicos en derecho romano, tesis doctoral, UAM, pendiente de publicación.

Scarcella, Agatina Stefania. La legislazione di Leone I, Milán: Giuffrè, 1997.

SeEcK, Otto, s.v. "Agentes in rebus", R.E. Pauly-Wissowa, I, 1894.

Serrigny, Denis. Droit public et administratif romain, París: Aug. Durand, Libraire-Éditeur, 1862.

Seyfarth, WolfGang. Römische Geschicbte Kaiserzeit, 2, Berlín: Akademie, 1974.

SinNigEN, WiLliam GURNEE. The roman secret service, Classical Journal, 1961-1962, pp. 65 ss.

Sinnigen, William GURnEE. "Chiefs of staff and chiefs of the secret service", Byzantinische Zeitschrift, 57, 1964, pp. 78 ss.

Stein, ERnSt. Histoire du bas-empire, I, París-Bruges: A.M. Hakkert, 1959.

STEIN, ERNST. Untersucbungen über das Officium der Prätorianerprefekten seit Diokletian, Ámsterdam: A.M. Hakkert, 1962.

SymE, RonALD. "The Imperial Finances under Domitian, Nerva and Trajan", JRS, 20, 1930, pp. 55 ss.

Trisciuoglio, ANDrea. Consideraciones sobre la responsabilidad civil y administrativa del magistrado en la experiencia romana, AA.VV. (ANTONIO FERNÁNDEZ DE BUJÁN, dir.), Hacia un derecho administrativo y fiscal romano, II, Madrid: Dykinson 2015, pp. 161-176.

ZAMORA MANZANO, JOSÉ LUIS. La administración penitenciaria en el derecho romano: gestión, tratamiento de los reclusos y mejora de la custodia carcelaria, Madrid: Dykinson, 2015. 